Keio J. Med. 32: 81-98, 1983

\title{
STUDIES ON CELL-MEDIATED IMMUNE FUNCTIONS OF PATIENTS WITH GYNECOLOGIC TUMOR - CYTOTOXIC ACTIVITY TO HUMAN OVARIAN CANCER CELL LINES AND REACTIVITY TO PHYTOHEMAGGLUTININ SHOWN BY LYMPHOCYTES
}

\author{
YOSHIO FUKUDA \\ Department of Obstetrics and Gynecology, School of Medicine, \\ Keio University, Tokyo, Japan \\ (Director: Prof. Soju Kurihara)
}

(Received for publication September 26, 1983)

\begin{abstract}
Peripheral blood lymphocytes collected from 23 healthy female volunteers, and 76 patients with gynecologic tumors including 33 ovarian cancers and 23 uterine cancers, 99 in total, was used to perform the allogeneic cytotoxicity test (to be referred to as "the test") and to evaluate for the blastogenic response to phytohemagglutinin (to be referred to as "the response"). The test was performed according to the method by Takasugi and Klein. Target cells used were two cell lines derived from human ovarian cancer, namely, HOC-21 from serous cystadenocarcinoma and YS-K from yolk sac tumor. The response was assayed on lymphocytes separated from the peripheral blood and on a very small amount of heparinized whole blood.

In the test, the higher the concentration of lymphocyte, the more cytotoxically it functioned. The cytotoxicity of lymphocytes from the patients with ovarian tumors, particularly ovarian cancers, was found to be higher than that from the patients with uterine tumors. Also, high cytotoxic activities were seen in the patients with dermoid cysts of ovary and choriocarcinomas. However, it was noted that the cytotoxicity was not always high in the patients whose histologic type was the same as that of the target cell. Cytotoxicity showed a slight decrease along with a progress of disease, but it was rather higher in recurrent cases.

By whole blood assay, the response was lower in the patients with malignant tumors than in the patients with benign tumors, and it was significantly low in advanced and recurrent cases. However, it was as normal as in the healthy subjects by lymphocyte assay.
\end{abstract}

\section{INTRODUCTION}

It is generally known that the cell-mediated immunity plays an important 
role in the anti-tumor immunity. A large number of studies have been made on the cell-mediated immunity and some of them have shown good results to evaluate the state and prognosis of patients with malignant tumors, while the studies are not many in patients with gynecologic tumors.

This study was attempted to clarify the anti-tumor immunity in the gynecological field by examining cytotoxicity against two kinds of ovarian cancer cell lines, which had been established in our laboratory, ${ }^{1,2}$ and blastogenic response to phytohemagglutinin (PHA) on peripheral blood lymphocytes from patients

Table 1

Location and histologic type of the subject tumors

\begin{tabular}{|c|c|c|c|c|}
\hline Subject & Histologic type & & No. & \\
\hline Healthy volunteer & & & 23 & \\
\hline \multirow[t]{7}{*}{ Ovarian cyst } & Serous cystadenoma & 3 & & \\
\hline & Mucinous cystadenoma & 2 & & \\
\hline & Dermoid cyst & 3 & & \\
\hline & Endometrial cyst & 2 & & \\
\hline & Lutein cyst & 1 & & \\
\hline & Parovarian cyst & 1 & & \\
\hline & & & 12 & \\
\hline \multirow[t]{3}{*}{ Uterine myoma } & Leiomyoma & 4 & & \\
\hline & Adenomyoma & 1 & & \\
\hline & & & 5 & \\
\hline \multirow[t]{8}{*}{ Ovarian ca. } & Serous cystadenoca. & 20 & & \\
\hline & Mucinous cystadenoca. & 5 & & \\
\hline & Clear cell adenoca. & 3 & & \\
\hline & Kruckenberg's tumor & 2 & & \\
\hline & Mixed epithelial ca. & 1 & & \\
\hline & Malignant teratoma & 1 & & \\
\hline & Embryonal ca. & 1 & & \\
\hline & & & 33 & \\
\hline \multirow[t]{3}{*}{ Uterine ca. } & Adenocarcinoma & 10 & & \\
\hline & Squamous cell ca. & 12 & & \\
\hline & & & 22 & \\
\hline Uterine sarcoma & Rhabdomyosarcoma & 1 & & \\
\hline Ca. of Fallopian tube & Adenocarcinoma & 1 & & \\
\hline Choriocarcinoma & & 2 & & \\
\hline Total & & & & 99 \\
\hline
\end{tabular}

Ca.: Carcinoma 
with gynecologic tumors, and the results were discussed as to whether these tests can be of help in grasping those patients.

\section{SUBJECTS}

Seventy-six patients with gynecologic tumors, seen in Keio University Hospital and its affiliated hospitals during the period from September 1978 to April 1980 were subjected to the tests in the present study. The patients consisted of 12 ovarian cyst, 5 uterine myoma, 33 ovarian carcinoma, 22 uterine carcinoma, 1 uterine sarcoma, 1 tubal carcinoma and 2 choriocarcinoma cases. These subjects were not treated previously except the recurrent cases which were readmitted after having received operation, chemotherapy, radiotherapy, or immunotherapy. The cases of ovarian carcinoma were classified into four groups according to the four stages approved by FIGO except the recurrent cases. In the recurrent cases, the interval between their first discharge from and re-admission to hospital ranged from 4 to 22 months, in the average of $16 \pm 7$ months. With 23 healthy females as the control, ages of the total 99 subjects ranged from 13 to 77 years, in the average of $46 \pm 15$ years (Tables 1 and 2 ).

Table 2

Summary of stage grouping for primary carcinoma of the ovary approved by FIGO

\begin{tabular}{|c|c|c|}
\hline \multicolumn{2}{|c|}{ Stage } & Extent \\
\hline \multirow[t]{4}{*}{ I } & & Limited to ovaries. \\
\hline & Ia & One ovary. No ascites. \\
\hline & $\mathrm{Ib}$ & Both ovaries. No ascites. \\
\hline & Ic & One or both ovaries. With ascites. \\
\hline \multirow[t]{4}{*}{ II } & & With pelvic extension. \\
\hline & IIa & Uterus and/or tubes. No ascites. \\
\hline & $\mathrm{IIb}$ & Other pelvis tissues. No ascites. \\
\hline & IIc & Other pelvic tissues. With ascites. \\
\hline III & & $\begin{array}{l}\text { Extension to small bowel/omentum in } \\
\text { true pelyis or intraperitoneal meta- } \\
\text { stases/retroperitoneal nodes. }\end{array}$ \\
\hline IV & & Distant organs. \\
\hline
\end{tabular}




\section{METHODS}

A. Cytotoxicity Test

1) Target Cells

The target cells for the cytotoxicity test were two lines of long-term cultured human ovarian cancer cells, namely HOC-211 (to be referred to as "HOC") derived from serious cystadenocarcinoma and $\mathrm{YS}^{2} \mathrm{~K}^{2}$ derived from yolk sac tumor (Photo 1).
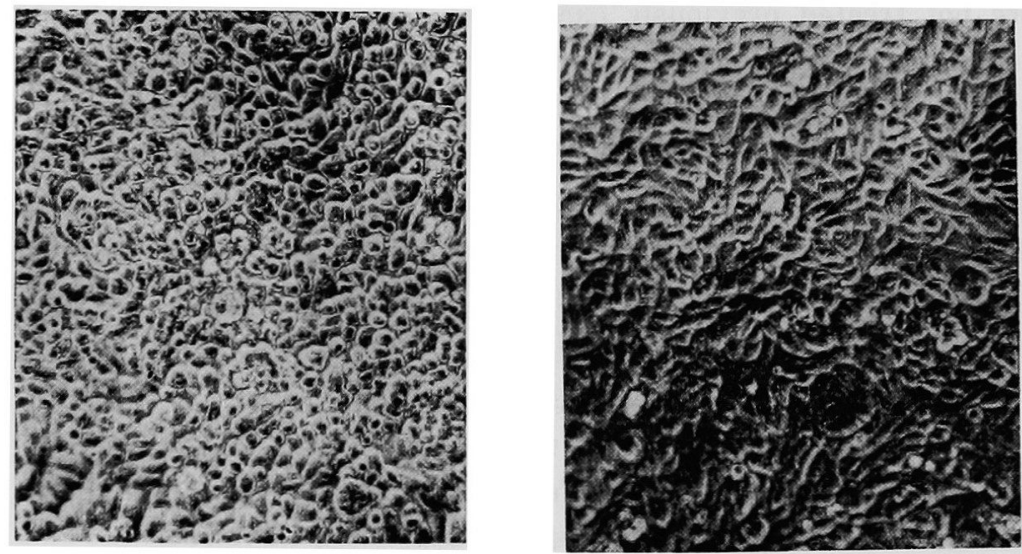

Photo 1 Two lines of human ovarian cancer cells (HOC, left; YS-K, right) growing in monolayer on a bottom surface of plaque bottle before tripsinisation under a phase-contrast microscope $(\times 100)$.

HOC has been subcultured for 300 generations since 1971 and its chromosome possessing a marker reveals near-diploid. The doubling time of the cells is 28 hours and their heterotransplantation to nude mice is possible. The histological appearance of such heterotransplanted cells reproduced the image of the original tumor tissue. YS-K has been subcultured for 150 generations since 1975 when the culture was started. The cells possessing a marker chromosome have been proved to have alpha fetoprotein by immunofluorescence staining, and the production of an HCG-like substance by the cells was also observed. A heterotransplantation of the cells into nude mice is possible and such transplanted cells show a close histological resemblance to the original tumor tissue.

As shown in Figure 1, these two lines of cancer cells were suspended in Eagle's MEM supplemented with $15 \%$ fetal calf serum (FCS), $100 \mu \mathrm{g} / \mathrm{ml}$ of $\mathrm{SM}$ and $100 \mathrm{U} / \mathrm{ml}$ of $\mathrm{PC}$ in a concentration of $2.5 \times 10^{4}$ cells $/ \mathrm{ml}$. Ten $\mu \mathrm{l}$ each of 
the suspension was dispensed into each well of a microtest plate (No. 3034, FALCON) and cultured in an incubator for 24 hours. After the incubation period, approximately $40 \%$ of the plated cells, i.e., about 100 cells, adhered to the bottom surface of each well.

\section{2) Effector Cells}

The lymphocytes were obtained from peripheral blood by the following technique: lymphocyte were separated from $10 \mathrm{ml}$ of heparinized peripheral blood taken from the forearm vein of the subject by Conray-Ficoll gradient centrifugation method, ${ }^{3}$ and washed three times with $\operatorname{PBS}(-)$. The washed cells were suspended in the culture medium to make the cell concentration of $2 \times 10^{6} / \mathrm{ml}$. The cell suspension contained lymphocytes at about $90 \%$, and their viability was approximately $100 \%$ according to the trypan blue exclusion.

\section{3) Microcytotoxicity Assay (MCA)}

A microcytotoxicity assay was carried out in accordance with the method by Takasugi and Klein. ${ }^{4}$ The wells of microtest plates, in which the target cells were seeded and cultured for 24 hours as described, were supplemented with $10 \mu \mathrm{l}$ each of the appropriately diluted lymphocyte suspension to make effector cells to target cells (E/T) ratios of 200, 100 and 50 (Photo 2). After further culturing for 48 hours, the wells were washed gently three times with $\operatorname{PBS}(-)$, stained with Giemsa solution after fixing with ethanol, and the target cells adhered to the bottom surface of each well were counted under a microscope

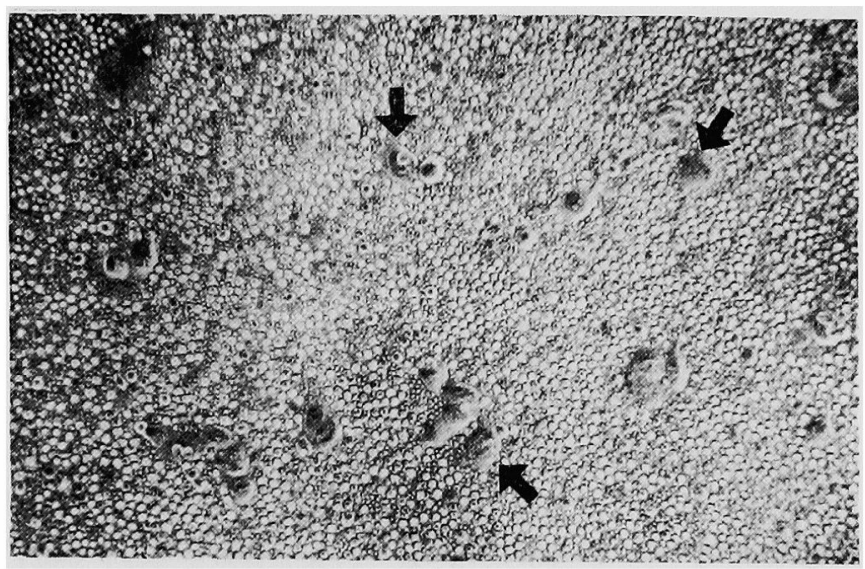

Photo 2 Human ovarian cancer cells (HOC) after adding lymphocytes (E/T ratio 200 ) on a well of microtest plate under a phase-contrast microscope $(\times 100) \Rightarrow$ target cell $(\mathrm{HOC})$. 

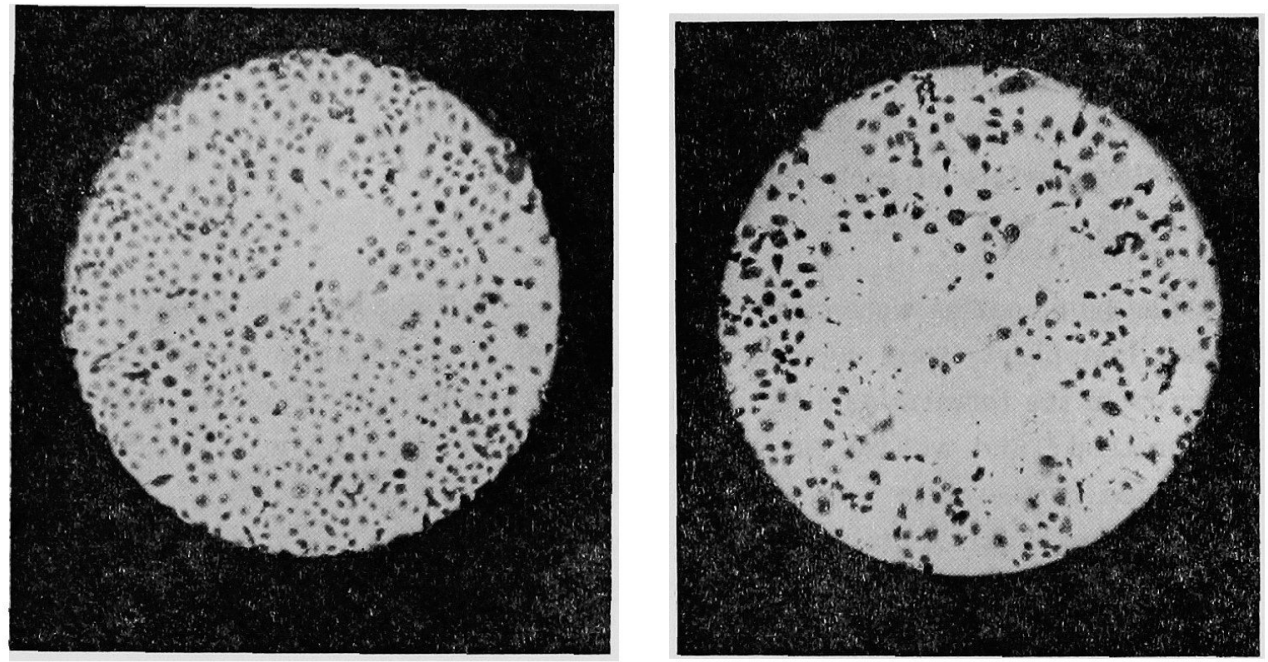

Photo 3 Human ovarian cancer cells (HOC) on a bottom surface of well of microtest plate after staining with Giemsa solution (without the application of lymphocytes, left; with that, right) $(\times 100)$.

\section{(Photo 3).}

Cytotoxicity was expressed by the reduction rate $(\%)$ of the number of cells adhered to the well caused by adding the lymphocytes. Four wells were used

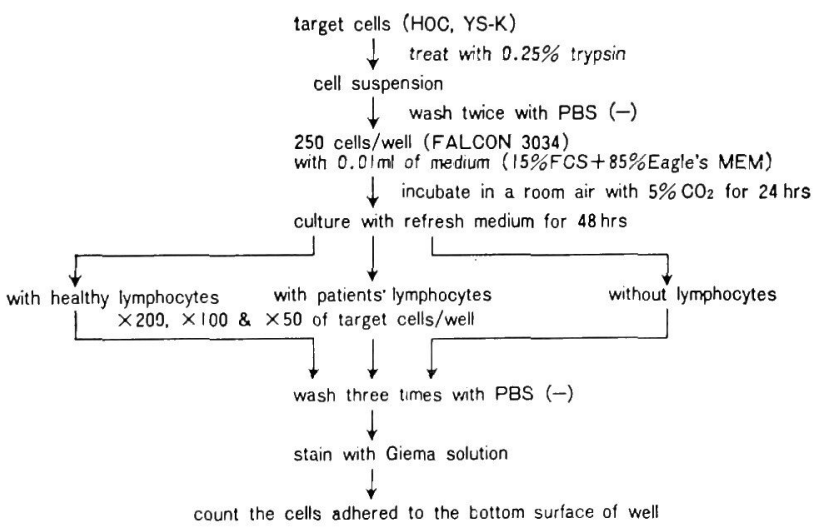

Reduction cytotoxicity $(\%)=\left(1-\frac{\text { No. of surviving target cells with lymphocytes }}{\text { No. of surviving target cells of control culture (without lymphocytes) }}\right) \times 100$

Fig. 1 Procedures of microcytotoxicity assay of peripheral blood lymphocytes from healthy volunteers and patients with gynecologic tumor. 
for each $\mathrm{E} / \mathrm{T}$ ratios, and the cytotoxicity was expressed by the mean value of the four wells (Fig. 1).

\section{B. Assay of PHA Response}

1) Assay of PHA Response of Lymphocytes Separated from Peripheral Blood (hereinafter called "Lymphocyte Assay")

Lymphocytes were separated from the heparinized peripheral blood as described, and after removing the plasma components their PHA response was assayed according to Khoo et al." One million lymphocytes suspended in $1 \mathrm{ml}$ of $15 \%$ FCS Eagle's MEM were cultured together with $10 \mu \mathrm{l}$ of $15 \mu \mathrm{g} / \mathrm{ml}$ PHA-P (Phytohemagglutinin-P, DIFCO) in a test tube (No. 1-56758, NUNCATOM) for 48 hours under the atmosphere of $5 \% \mathrm{CO}_{2}$ and $95 \%$ air at $37^{\circ} \mathrm{C}$. Then, $1 \mu \mathrm{Ci}$ of ${ }^{3} \mathrm{H}$-thymidine ( $1 \mu \mathrm{Ci} / \mu \mathrm{l}$, Amersham International) was added to the culture, and after another 24-hour culture, the culture cells were harvested on a millipore filter (pore size $1.2 \mu$ and diameter $2.5 \mathrm{~mm}$ ) by suction. The filter was washed with $5 \mathrm{ml}$ of physiological saline and $10 \mathrm{ml}$ of $5 \%$ trichloroacetic acid, and then dried. The filter was placed in $5 \mathrm{ml}$ of a scintillator liquid, and the radioactivity incorporated by the cells on the filter was counted on a liquid scintillation counter.

2) Assay of PHA Response by Use of Whole Blood (Whole Blood Assay)

The assay was performed according to Mizoguchi et al. ${ }^{6}$ To a test tube containing $0.9 \mathrm{ml}$ of Eagle's MEM, $0.1 \mathrm{ml}$ of the heparinized peripheral blood and $10 \mu \mathrm{l}$ of $15 \mu \mathrm{g} / \mathrm{ml}$ of PHA-P were added, and the blood was cultured for 48 hours. Then, $1 \mu \mathrm{Ci}$ of ${ }^{3} \mathrm{H}$-thymidine was added to the culture, and after 24 hours of further culture, erythrocytes in the culture were hemolyzed by adding $5 \mathrm{ml}$ of distilled water. The hemolyzed culture cells were collected on a millipore filter. The filter was processed and used for count of radioactivity as described in the preceding section.

The stimulation index (S.I.) was calculated by the ratio of the ${ }^{3} \mathrm{H}$-thymidine uptake of the PHA-stimulated group to that of the non-stimulated group.

$$
\text { S.I. }=\frac{\text { Uptake of stimulated group-background }}{\text { Uptake of non-stimulated group-background }}
$$

Each specimen was measured in duplicate and the mean obtained was designated as the value of measurement.

A statistic study was made by the student t-test, and $p$ values less than 0.05 were regarded as significant. 


\section{RESULTS}

1) E/T Ratio and Cytotoxicity

In most of cases where the $\mathrm{E} / \mathrm{T}$ ratio was 50,100 , or 200 , dose responses roughly in proportion to such ratios were observed, and higher cytotoxicities were indicated along with increasing $\mathrm{E} / \mathrm{T}$ ratios. Figure 2 shows the results of the 12 ovarian cyst and 30 ovarian cancer cases.

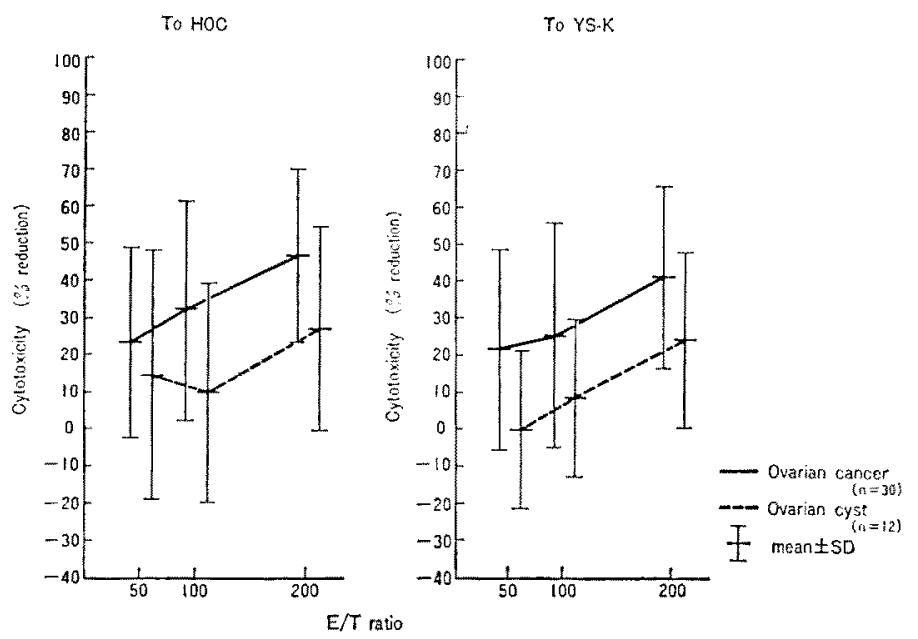

Fig. 2 Relation between $\mathrm{E} / \mathrm{T}$ ratio and cytotoxicity by MCA in patients with ovarian cyst (--) or cancer (-).

2) Cytotoxicity and PHA Response in Relation to the Location of the Primary Tumor

The lymphocyte cytotoxicity to HOC as well as to YS-K was higher in the ovarian tumor cases than in the uterine tumor cases, and particularly, markedly high cytotoxicity-significantly to HOC, but not to YS-K-was observed in the ovarian malignant tumor cases as compared to the uterine malignant tumor cases where it was almost the same as that shown in the ovarian benign tumor cases. In the uterine benign tumor cases, the cytotoxicity was lowest except the healthy controls.

A significant difference was observed in the cytotoxicity to HOC by different sites of the primary tumor among the malignant tumor cases. Also, it was recognized between the ovarian malignant tumor cases and the benign tumor cases in that to HOC as well as to YS-K (Table 3 and Fig. 3 ). 
No differences were observed in the PHA response by different sites of the primary tumor among the benign tumor cases as well as among the malignant tumor cases. The benign tumor cases showed about even or high response as compared to that of the healthy controls. The response in the malignant tumor cases was high by lymphocyte assay but significantly low by whole blood assay (Table 3).

Table 3

Cytotoxicity to two lines of ovarian cancer cells and PHA response of lymphocytes or whole blood from ovarian or uterine tumor cases

\begin{tabular}{c|l|c|c|c|c}
\hline \multirow{2}{*}{ Control } & \multirow{2}{*}{ Organ } & \multicolumn{2}{|c|}{ Cytotoxicity (E/T ratio 200) } & \multicolumn{2}{|c}{ PHA Response (S.I.) } \\
\cline { 3 - 6 } & & To HOC & To YS-K & Of Lymphocyte & Of Whole Blood \\
\hline \multirow{2}{*}{ Benign tumor } & $9.9 \pm 48.0$ & $15.4 \pm 11.0$ & $79.5 \pm 32.2$ & $79.8 \pm 18.7$ \\
\hline \multirow{2}{*}{ Malignant tumer } & Ovary & $27.5 \pm 28.3$ & $24.7 \pm 23.1$ & $130.1 \pm 17.0$ & $70.2 \pm 22.3$ \\
& Uterus & $19.1 \pm 17.8$ & $19.7 \pm 24.5$ & $187.4 \pm 50.1$ & $154.1 \pm 21.7$ \\
\hline & Ovary & $46.9 \pm 23.5$ & $41.2 \pm 24.7$ & $112.6 \pm 7.8$ & $39.3 \pm 22.0$ \\
& Uterus & $27.6 \pm 29.8$ & $27.9 \pm 20.5$ & $147.1 \pm 41.4$ & $38.6 \pm 30.6$ \\
\hline
\end{tabular}

TO HOO

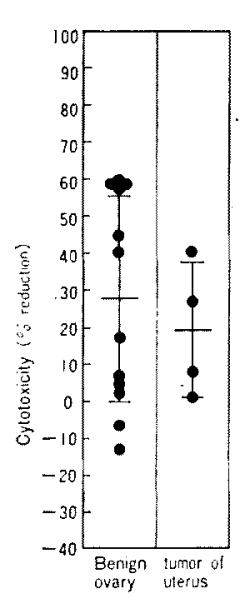

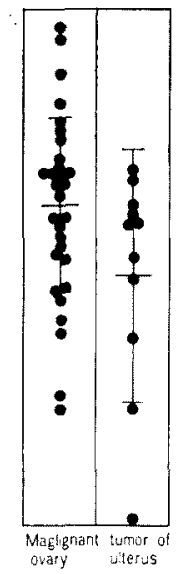

To YS-K
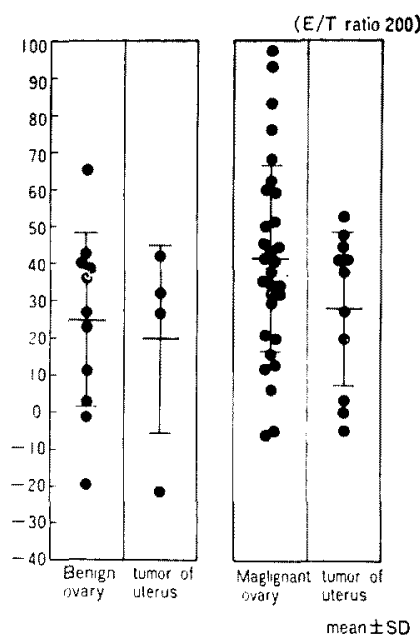

Fig. 3 Relation between location of primary tumor and cytotoxicity by MCA in ovarian or uterine tumor cases. 
Table 4

Lymphocyte cytotoxicity to two lines of ovarian cancer cells according to histologic types of tumor

$(\mathrm{E} / \mathrm{T}$ ratio 200$)$

\begin{tabular}{|c|c|c|c|}
\hline Organ & Histologic type & To HOC & To YS-K \\
\hline Ovary & $\begin{array}{l}\text { Serous cystadenoma } \\
\text { Mucinous cystadenoma } \\
\text { Dermoid cyst }\end{array}$ & $\begin{array}{l}23.0 \pm 32.7 \\
30.8 \pm 40.6 \\
28.3 \pm 36.9\end{array}$ & $\begin{array}{l}12.3 \pm 13.9 \\
31.1 \pm 11.2 \\
45.7 \pm 17.6\end{array}$ \\
\hline Uterus & Leiomyoma & $12.0 \pm 13.3$ & $12.4 \pm 29.7$ \\
\hline \multicolumn{2}{|c|}{ Benign group* } & $23.7 \pm 27.3$ & $22.6 \pm 22.5$ \\
\hline Ovary & $\begin{array}{l}\text { Serous cystadenocarcinoma } \\
\text { Mucinous cystadenocarcinoma } \\
\text { Clear cell adenocarcinoma }\end{array}$ & $\begin{array}{l}44.0 \pm 28.4 \\
57.8 \pm 17.4 \\
38.0 \pm 14.2\end{array}$ & $\begin{array}{l}43.5 \pm 25.7 \\
40.6 \pm 24.7 \\
43.2 \pm 23.6\end{array}$ \\
\hline \multirow[t]{3}{*}{ Uterus } & $\begin{array}{l}\text { Adenocarcinoma } \\
\text { Squamous cell carcinoma }\end{array}$ & $\begin{array}{l}27.1 \pm 23.5 \\
28.3 \pm 39.1\end{array}$ & $\begin{array}{l}29.3 \pm 24.1 \\
26.3 \pm 17.9\end{array}$ \\
\hline & Choriocarcinoma & $50.1 \pm 29.6$ & $58.0 \pm 1.1$ \\
\hline & Malignant group & $44.5 \pm 27.8$ & $38.6 \pm 25.2$ \\
\hline
\end{tabular}

3) Anti-tumor Lymphocyte Cytotoxicity in Relation to Histologic Types of Tumor

As shown in Table 4, the cytotoxicity to HOC as well as to YS-K was high in the ovarian adenocarcinoma cases. As compared with the above, the cytotoxicity was low in the uterine adenocarcinoma and squamous cell carcinoma cases where it was almost the same as that observed in the ovarian mucinous cystadenoma and dermoid cyst cases, except anti-YS-K cytotoxicity in the dermoid cyst cases which was as high as that in the ovarian adenocarcinoma cases. In the ovarian serous cystadenoma cases, the cytotoxicity was low, and anti-YS-K cytotoxicity was at the level of that in the healthy controls. In the uterine leiomyoma cases, it was at the level of the healthy controls. In the choriocarcinoma cases, a markedly high cytotoxicity to $\mathrm{HOC}$ as well as to $\mathrm{YS}-\mathrm{K}$ was observed.

A significant difference was recognized between the benign group and the cases of ovarian adenocarcinoma in the cytotoxicity to HOC as well as to YS-K.

4) Cytotoxicity and PHA Response in Relation to Clinical Stages of Disease Observations following the classification of clinical stages by FIGO (Table 
2) revealed that the cytotoxicity to HOC was about even or slightly decreased from Stage I to IV in the ovarian carcinoma cases, but it was high in the recurrent cases. The cytotoxicity to YS-K showed a similar trend to that of the cytotoxicity to HOC until Stage III, but in Stage IV, it was high and further became higher in the recurrent cases (Table 5 and Fig. 4).

A significant difference was observed in the cytotoxicity to HOC as well as to YS-K between the benign group and the recurrent cases of ovarian carcinoma. Also, there was a significant difference in the cytotoxicity to YS-K between the

Table 5

Lymphocyte cytotoxicity according to clinical staging of ovarian carcinoma

\begin{tabular}{|c|c|c|c|}
\hline & \multirow{2}{*}{ Stage } & \multicolumn{2}{|c|}{ Cytotoxicity (E/T ratio 200 ) } \\
\hline & & To HOC & To YS-K \\
\hline \multicolumn{2}{|l|}{ Benign group* } & $23.7 \pm 27.3$ & $22.6 \pm 22.5$ \\
\hline \multirow{5}{*}{ Ovarian carcinoma } & I & $43.2 \pm 17.9$ & $30.7 \pm 22.7$ \\
\hline & II & $42.0 \pm 14.7$ & $30.4 \pm 14.4$ \\
\hline & III & $39.3 \pm 31.0$ & $28.5 \pm 21.9$ \\
\hline & IV & $41.2 \pm 50.1$ & $42.8 \pm 36.2$ \\
\hline & Recurrence & $58.2 \pm 20.5$ & $64.6 \pm 20.8$ \\
\hline
\end{tabular}

* It includes the healthy subjects.

mean $\pm \mathrm{SD}$
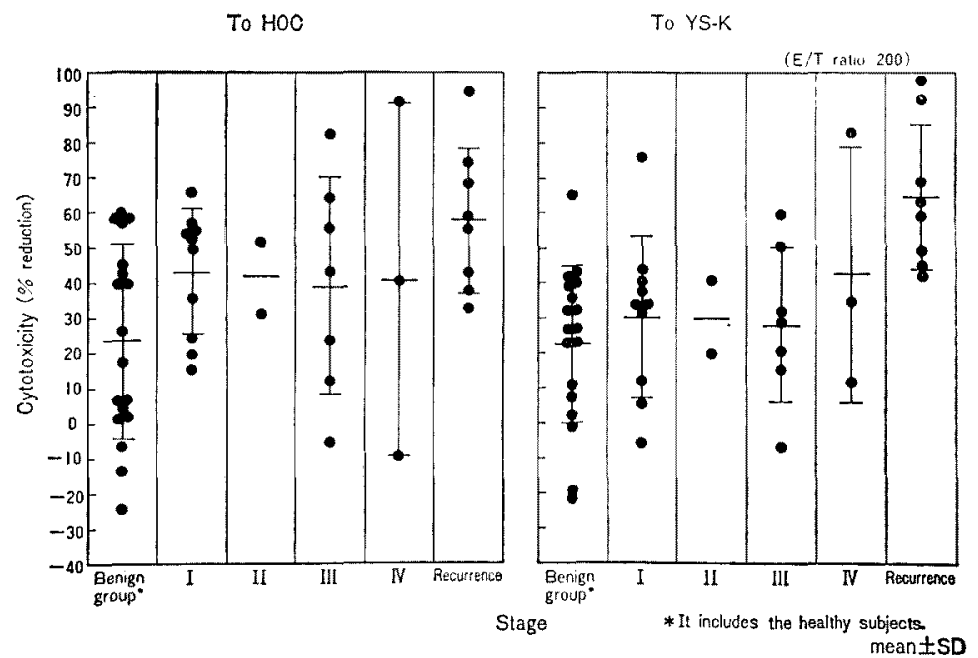

Fig. 4 Relation between clinical stages and cytotoxicity in ovarian carcinoma cases. 
cases in Stage I or III and the recurrent cases of ovarian carcinoma.

In the uterine carcinoma cases, a trend of decrease was observed in both cytotoxicities along with the progress of stage from $I$ (to $\mathrm{HOC}, 37.4 \pm 24.0$; to YS-K, $29.2 \pm 30.3$ ) to II (to HOC, $16.4 \pm 35.4$; to YS-K, $23.7 \pm 29.1$ ) and to III (to HOC, $21.4 \pm 42.9$; to YS-K, $23.5 \pm 19.5$ ), however, the value was rather high in Stage IV and in the recurrent cases (to HOC, $36.7 \pm 6.6$; to YS-K, $39.3 \pm 2.1$ ).

The PHA response by whole blood assay was significantly lower in the recurrent cases of ovarian carcinoma $(31.9 \pm 3.3)$ than in the healthy controls $(79.8 \pm$ 18.7). In the uterine carcinoma cases, the response was high and normal in Stage I, however, the value decreased remarkably along with the progress of stage from II to III. A significant difference was observed between the healthy controls, or Stage I or II patients, and Stage III patients. The responses in Stage IV and recurrent cases which were slightly higher than those shown in Stage III patients were significantly lower than those shown in the healthy controls, but not significantly lower than those in Stage I or II patients (Table 6).

Table 6

Lymphocyte response to PHA by use of whole blood according to clinical staging of uterine carcinoma

\begin{tabular}{c|c|c}
\hline & Stage & $\begin{array}{c}\text { PHA Response (S.I.) } \\
\text { of Whole Blood }\end{array}$ \\
\hline Control & & $79.8 \pm 18.7$ \\
\hline Uterine carcinoma & I & $95.1 \pm 54.5$ \\
& II & $62.8 \pm 28.3$ \\
& III & $16.3 \pm 9.8$ \\
& IV & $23.5 \pm 3.3$ \\
& Recurrence & $25.8 \pm 3.2$ \\
\hline
\end{tabular}

5) Comparison of Cytotoxicities to Two Lines of Target Cells and PHA Responses by Two Assays in the Same Case

Of 20 cases of ovarian serous cystadenocarcinoma having the same histologic type with HOC taken as examples, in 13 cases $(65 \%)$ there was a difference exceeding $10 \%$ between the cytotoxicity to $\mathrm{HOC}$ and that to $\mathrm{YS}-\mathrm{K}$; in 6 cases (30\%) out of which, the cytotoxicity to HOC was higher than the other and in the remaining 7 cases $(35 \%)$, the former was lower than the latter. The mean values were almost the same resulting in no significance (Fig. 5).

In comparison of the PHA responses by lymphocyte and whole blood assays, 
Fig. 5 Relation between anti-HOC and anti-YS-K cytotoxicities in the same patient (-O) with serous cystadenocarcinoma of ovary.

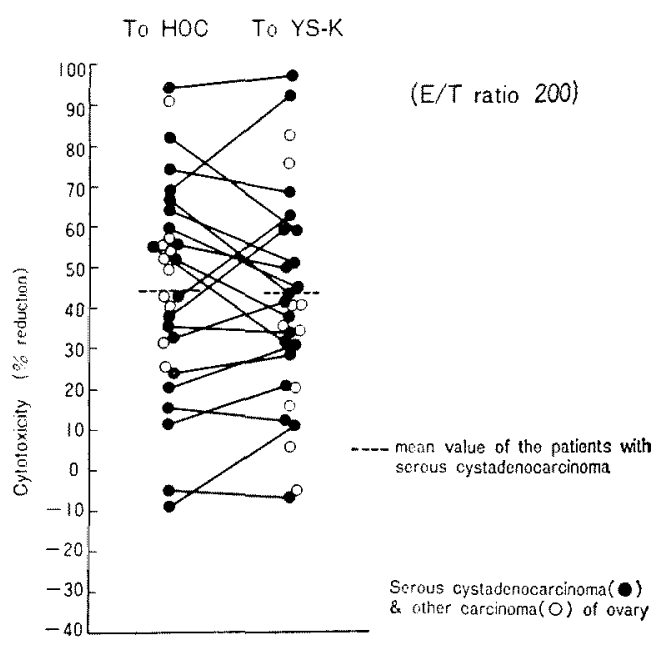

no difference was observed in the healthy controls $(79.5 \pm 32.2$ by lymphocyte assay; $79.8 \pm 18.7$ by whole blood assay) and the benign tumor cases ( $158.7 \pm 45.0$ by lymphocyte assay; $103.7 \pm 49.8$ by whole blood assay) by either assay as the benign tumor cases indicated normal responses as is seen in the healthy controls. Although the PHA response in the malignant tumor cases was normal by lymphocyte assay $(133.3 \pm 35.1)$, it was significantly low by whole blood assay $(38.8 \pm 28.1$ ) (Table 3 ).

\section{DISCUSSION}

Since the colony inhibition test was introduced by Hellström et al., ${ }^{7}$ the cytotoxicity test has been used as one of the effective method in investigating cell-mediated immune functions in vitro. The microcytotoxicity assay introduced by Takasugi and Klein ${ }^{4}$ in 1970 is a comparatively simple method, and a large number of studies have been reported by use of this method. The studies in the early days, e.g., on ovarian and uterine carcinomas by Di Saia et al., ${ }^{8,9}$ on urinary bladder carcinoma by Bubenik et al. ${ }^{10}$ and O'Toole et al.,11 on colonic carcinoma and melanoma by Hellström et al., ${ }^{12,13}$ on breast carcinoma by Fossati et $a l .,{ }^{14}$ and on melanoma by De Vries et al..$^{15}$ suggested that lymphocytes of tumor-bearing patients showed cytotoxicity in vitro not only to autochthonous tumor target cells but also to allogeneic tumor target cells of a similar histologic type, but no cytotoxicity to normal target cells, and that lymphocytes of healthy persons did not show any cytotoxicity to tumor target cells. These studies also demonstrated the presence of a blocking antibody (or blocking factor) in sera of tumorbearing patients that inhibits the lymphocyte cytotoxicity. Afterwards, Takasugi 


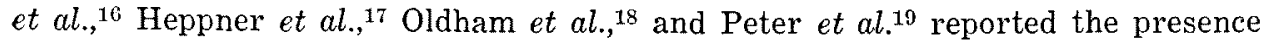
of lymphocytes that exhibit high cytotoxic activity non-specifically in healthy persons, and also showed negative results with respect to the cytotoxicity specific to the histologic type of tumor. In addition, there are still many problems in the anti-tumor cytotoxicity test, such as the kinds of tumor cells to be used as target cells, preparations of lymphocytes and their purity, or the subpopulations of lymphocytes to be used as effector cells, and cytotoxicity caused by interventions of allogeneic histocompatibility antigens, etc. Nowadays, it is generally accepted that anti-tumor lymphocyte cytotoxicity is useful as a yardstick for determination of the non-specific cell-mediated anti-tumor immune function, though there is a possibility to include the cytotoxicity specific to the tumor. ${ }^{20}$

In this study, the result of the relation between the $E / T$ ratio and the cytotoxicity in MCA showed that, if the $\mathrm{E} / \mathrm{T}$ ratio was high, the toxicity was also high in most of healthy and tumor-bearing cases. In other words, the result suggested that the higher the concentration of lymphocytes, the more cytotoxically they acted.

The fact that lymphocytes of the ovarian tumor cases, particularly ovarian cancer cases, showed cytotoxicities to two lines of allogeneic ovarian cancer cells higher than those observed in the uterine tumor cases suggested the possibility of MCA containing a cytotoxicity specific to tumor. Regarding a cytotoxicity specific to tumor, there are various reports, some affirming it, others negating it. Di Saia et al. ${ }^{8,9}$ reported that peripheral blood lymphocytes of patients with ovarian carcinoma showed a cytotoxicity specific to allogeneic ovarian carcinoma cells. They also obtained similar observations regarding allogeneic carcinoma cells of uterine cervix. According to Mashiba et al., ${ }^{21}$ peripheral blood lymphocytes of patients with carcinoma of uterine cervix showed a high cytotoxicity to allogeneic uterine cervical carcinoma cells, but no cytotoxicity was observed in healthy persons and patients with uterine myoma. There are many reports on the presence of cytotoxicity specific to allogeneic tumor cells in fields other than the gynecological field. ${ }^{10-15}$

Further, when cytotoxicities were studied by histologic types of tumor, patients with ovarian adenocarcinoma showed a high cytotoxicity to HOC derived from ovarian adenocarcinoma. Such fact seemed to suggest the cytotoxicity specific to the histologic type, but the results that threw some doubt upon the above suggestion were also obtained, namely, patients with ovarian dermoid cyst, ovarian adenocarcinoma or choriocarcinoma also showed a high toxicity to YS-K derived from ovarian embryonal carcinoma. As a result of the investigation of the cases where the histologic type was similar to that of $\mathrm{HOC}$, in order to find out whether there was a difference between anti-HOC and anti-YS-K cytotoxicities shown by one patient, no cytotoxicity specific to HOC was observed as compared 
to YS-K. Here again, the results denied the presence of cytotoxicity specific to the histologic type of allogeneic target cells.

In view of the clinical application, to learn the relation between the clinical stage of disease and the cytotoxicity is very important. This study demonstrated that the cytotoxicity in ovarian or uterine carcinoma cases showed a slight decrease along the progressing course of disease, however, it was high in recurrent cases. The cytotoxicities to the two lines of target cells observed in recurrent cases of ovarian carcinoma were significantly higher than those shown in healthy persons and benign cases. These results were characteristic as compared to various reports in which they said that the cytotoxicity decreased along with the progress of disease, ${ }^{2122}$ or that the cytotoxicity had not much relation with the clinical stage of disease, ${ }^{15}$ and no reports of a similar nature to the present one had been published on malignant tumors in other fields or on ovarian cancers. Recently Dini and Faiferman ${ }^{23}$ reported on the cytotoxicity in patients with cervical squamous malignancy followed over a relatively long period of time. They demonstrated that most of the patients with recurrent disease expressed strong cytotoxic responses, and described that the presence of antigenic stimulation (persistence of tumor) was necessary for retention of cell-mediated cytotoxic responses which could only be used as a complementary parameter in the overall periodic evaluation and surveillance of cancer patients.

Ovary has special characteristics which are not seen in other organs, namely, that it consists of embryonic tissues that produce hormones which may have a possibility to be regarded as antigens, and the types of tumors that develop in the ovary are greatly diversified. The reason for a greater difference on the cytotoxicity among each clinical stage of disease in the examination using YS-K than in that using HOC may be attributable to the fact that YS-K is an embryonal carcinoma cell line which has a possibility to have more elements to work as a marker than HOC does. Many reasons for the high cytotoxicity in the recurrent cases are presumable, i.e., in a sense, they received treatment already; their immune mechanisms had been constantly stimulated by the prolonged presence of cancer tissues due to insufficient therapy and further the diversified antigenic stimulation peculiar to ovarian cancer; their lesions were of the type to disseminate intraperitoneally in wider areas unlike the localized lesion of the early cancer; and-this was clinically experienced-general responses are probably maintained in ovarian cancer patients even in advanced or recurrent cases because their nutritional conditions are relatively better in such cases than in cancer cases of other organs such as respiratory, digestive systems, etc.

PHA which is a non-specific mitogen acts on $\mathrm{T}$ cells to activate them. Therefore, the lymphocyte response to PHA (PHA response) reflects the activity of $\mathrm{T}$ cells ${ }^{24}$ and correlates well to the delayed hypersensitivity reaction. At present, 
it is widely used clinically as a parameter for the non-specific cell-mediated immunity in tumor-bearing patients.

From the results of this study, no characteristic trend by the location of the primary tumor was seen in the PHA response. However, the whole blood assay indicated a fairly clear difference between the benign and malignant types histologically though the lymphocyte assay showed no difference. Namely, the response by whole blood assay was significantly low in the malignant tumor cases as compared to the benign tumor cases. Also, in the relation between the clinical stage of disease and the PHA response, significantly low values were recognized by whole blood assay in the advanced and recurrent cases of ovarian or uterine carcinoma.

There are reports on the findings of a decrease in $\mathrm{PHA}$ response in the patients with ovarian cancer (lymphocyte assay) by Khoo et al.; a reverse correlation between the decrease of PHA response and survival at 6 months by Wolff et al. ${ }^{25}$; and a decrease in PHA response (whole blood assay) regardless of the clinical stage of disease by Takizawa et al. ${ }^{26}$ Further in the uterine cancer cases, a similar decrease was observed by Khoo et al., ${ }^{5}$ and Mashiba et al. ${ }^{21}$ reported a decrease of PHA response (lymphocyte assay) starting from Stage I and they observed a marked decrease in Stage IV and in recurrent cases.

As above, there are many reports on the decrease in PHA response in cancerbearing patients or such occurred along the course of progress of disease. And it is presumed that the cause of such decreases may be attributable to the deteriorated function of lymphocyte itself $^{27}$ or a plasma factor. ${ }^{28}$ Therefore, the results of this study pose the presumption that the decrease in PHA response seen in the female genital tract cancer cases is caused mainly by the plasma factor rather than the deteriorated function of lymphocyte itself, and they further suggested the possibility that the function of lymphocyte itself was preserved comparatively well even in the advanced or recurrent cases. This was also presumed from the fact that a decrease in cytotoxicity along with the progress of cancer was slight in MCA.

Because of the complexity in interpreting the results of the allogeneic cytotoxicity test, a great deal of difficulty in evaluating the state and prognosis of disease is expected. However, the author believes that in the future, the cytotoxicity test would be able to serve as an effective aid when more specifically selected target cells and preparations of purer lymphocytes classified into subpopulations become available, and that the PHA response by whole blood assay could be an index of the cell-mediated immunity in a state closer to that in vivo.

\section{ACKNOWLEDGEMENT}

The author would like to express his deep gratitudes to Professor Soju 
Kurihara for his valuable direction and revision, and to Associate Prof. Shozo Tamura for his helpful suggestions and encouragements during the course of this study. Many thanks are also tendered to Dr. Takuro Yamada, Department of Gynecology, National Cancer Center, and the senior and junior staffs of the 1st Laboratory, Dept. of Obstet. and Gynec., Keio Univ., for their supports and advices during the investigation.

A part of this report was introduced at the 32nd Annual Scientific Meeting of the Japan Society of Obstetrics and Gynecology, Tokyo, May 1980.

\section{REFERENCES}

1. Yamada, T.: The cellular biology of a newly established cell line of human ovarian adenocarcinoma in vitro. Keio J. Med. 23: 53-70, 1974

2. Yamada, T., Kasamatsu, T., Tamura, S. et al.: Long term subculture of human ovarian yolk sac tumor, ACTA OBST GYNAEC JPN 28(9) : 1028, 1976 (in Japanese)

3. Tsuji, K.: Separation of lymphocyte by gradient centrifugation method, Conray 400-Ficoll method, Immunological experimental method. Edited by Japanese Soc. of Immunology 443-446, 1971 (in Japanese)

4. Takasugi, M. and Klein, E.: A microassay for cell-mediated immunity. Transplantation 9: 219-227, 1970

5. Khoo, S. K., Tillack, S.V. and Mackay, E. V.: Cell-mediated immunity: Effect of female genital tract cancer, pregnancy and immunosuppressive drugs. Aust. N.Z.J. Obstet. Gynaec. 15: 156-161, 1975

6. Mizoguchi, Y., Yamada, T. and Morisawa, S.: Blastoid transformation and MIF production tests by use of microquantitative peripheral whole blood, Immunological experimental method. Edited by Japanese Soc. of Immunology 688-691, 1973 (in Japanese)

7. Hellström, I.: A colony technique for demonstration of tumor cell destruction by lymphoid cells in vitro. Int. J. Cancer 2: 65-68, 1967

8. Di Saia, P.J., Rutledge, F. N., Smith, J. P. et al.: Cell-mediated immune reaction to two gynecologic malignant tumors. Cancer 28: 1129-1137, 1971

9. Di Saia, P. J., Sinkovics, J. G., Rutledge, F. N. et al.: Cell-mediated immunity to human malignant cells. Am. J. Obstet. Gynecol. 114: 979-989, 1972

10. Bubenik, J., Perlmann, P., Helmstein, K. et al.: Immune response to urinary bladder tumors in man. Int. J. Cancer 5: 39-46, 1970

11. O'Toole, C., Perlmann, P., Unsgaard, B. et al.: Cellular immunity to human urinary bladder carcinoma, I. Correlation to clinical stage and radiotherapy. Int. J. Cancer 10: 77-91, 1972

12. Hellström, I., Hellström, K. E. and Shepard, T.H.: Cell-mediated immunity against antigens common to human colonic carcinomas and fetal gut epithelium. Int. J. Cancer 6: 346-351, 1970

13. Hellström, I., Hellström, K. E. and Sjögren, H. O.: Some recent information on "blocking antibodies" as studied in vitro. Transpl. Proc. 3: 1221-1227, 1971

14. Fossati, G., Canevari, S., Della Porta, G. et al.: Cellular immunity to human breast carcinoma. Int. J. Cancer 10: 391-396, 1972

15. De Vries, J.E., Rümke, P. and Bernheim, J.L.: Cytotoxic lymphocytes in melanoma patients. Int. J. Cancer 9: 567-576, 1972

16. Takasugi, M., Mickey, M. R. and Terasaki, P. I.: Reactivity of lymphocytes from normal persons on cultured tumor cells. Cancer Res. 33: 2898-2902, 1973

17. Heppner, G., Henry, E., Stolbach, L. et al.: Problems in the clinical use of the microcytotoxicity assay for measuring cell-mediated immunity to tumor cells. Cancer Res. 35: 1931-1937, 1975 
18. Oldham, R. K., Djeu, J.Y., Cannon, G. B. et al.: Cellular microcytotoxicity in human tumor systems: Analysis of results. J. Nat. Cancer Inst. 55: 1305-1318, 1975

19. Peter, H.H., Kalden, J.R., Seeland, P. et al.: Humoral and cellular immune reactions 'in vitro' against allogeneic and autologous human melanoma cells. Clin. Exp. Immunol. 20: 193-207, 1975

20. Kikuchi, K. and Uchizawa, K.: Cancer and immunity, clinical significance of cellular immunity. CLINIC ALL-ROUND 26: 2874-2882, 1977 (in Japanese)

21. Mashiba, H., Matsunaga, K., Ueno, M. et al.: Cell-mediated cytotoxicity in vitro of human lymphocytes against a cervical cancer cell line. Gann 68: 53-58, 1977

22. Yasumoto, K., Ohta, M. and Nomoto, K.: Cytotoxic activity of lymphocytes to bronchogenic carcinoma cells in patients with lung cancer. Gann 67:505-511, 1976

23. Dini, M. M. and Faiferman, I.: Sequential in vitro reactivity of lymphocytes from patients with cervical squamous malignancy in a cytotoxicity assay. Am. J. Obstet. Gynecol. 144: 341-345, 1982

24. Doenhoff, M. J., Daview, A. J. S., Leuchars, E. et al.: The thymus and circulating lymphocytes of mice. Proc. Roy. Soc. Lond. B. 176: 69-85, 1970

25. Wolf, J. P. and De Oliveira, C. F.: Lymphocytes in patients with ovarian cancer. Obst. \& Gynec. 45: 656-658, 1975

26. Takizawa, K., Kawabata, M., Kawana, T. et al.: Evaluation of the lymphocyte responses to phytohemagglutinin (PHA) using microquantitative peripheral whole blood culture technique in the management of patients with ovarian cancer. J. Jpn. Soc. Cancer Ther. 16(6): 1239-1247, 1981 (in Japanese)

27. Thomas, J. W., Coy, P., Lewis, H. S. et al.: Effect of therapeutic irradiation on lymphocyte transformation in lung cancer. Cancer 27: 1046-1050, 1971

28. Sample, W. F., Gertner, H. R. Jr. and Chretien, P. B.: Inhibition of phytohemagglutinin-induced in vitro lymphocyte transformation by serum from patients with carcinoma. J. Nat. Cancer Inst. 46: 1291-1297, 1971 